Cancer Investigation 2009

\title{
ONCOGENE-DRIVEN HEMOSTATIC CHANGES IN CANCER
}

\author{
Janusz Rak ${ }^{1,2,}$, Joanne $\mathrm{Yu}^{3}$ \& Chloe Milsom ${ }^{2}$
}

${ }^{1}$ Montreal Children's Hospital, McGill University, QC, Canada

${ }^{2}$ Henderson Research Centre, McMaster University, Hamilton, ON, Canada

${ }^{3}$ University of Toronto, Toronto, ON, Canada

"Correspondence should be addressed to: Janusz Rak, Montreal Children's Hospital Research Institute, 4060 Ste Catherine West, Montreal, QC, H3Z 3Z2, Canada; Tel: 514-412-4400 ext. 22342; janusz.rak@mcgill.ca

Key words. Cancer coagulopathy, Trousseau syndrome, tissue factor, oncogenes, angiogenesis, tumor initiating cells 


\section{ABSTRACT.}

A common feature in progression of multiple human malignancies is the protracted deregulation of the coagulation system, often referred to as cancer coagulopathy. The genesis of this syndrome can be traced to changes in the tumour vascular interface, formed through vascular invasion, angiogenesis and metastasis. The resulting contact between cancer cells and the circulating components of the coagulation system compromise the regulatory barriers that normally control physiological haemostasis. In addition, cancer cells and their stroma often exhibit procoagulant properties. While these changes have long been thought to be unspecific in nature evidence now exists to suggest that cancer coagulopathy and the related Trousseau syndrome are a function of the genetic tumor progression. Indeed, the expression of several effector molecules of the coagulation and fibrinolytic systems, including: tissue factor (TF), plasminogen activator inhibitor 1 (PAI-1), cyclooxygenase 2 (COX-2) or urokinase (uPA) are often direct regulatory targets of oncogenes (K-ras, EGFR, HER-2, c-MET) and tumour suppressors (p53, PTEN). Moreover, oncogenic alterations act on coagulation indirectly by

driving formation of leaky vessels, metastasis or inflammation. These procoagulant influences of oncogenic pathways are modulated by hypoxia, stress responses and cellular differentiation, the latter involving formation of cancer stem cells and their niches to which coagulation factors may contribute. It is possible that targeting cancer-related coagulopathy may require more cancerspecific measures, to achieve improved thromboprophylaxis and impact patients survival. 


\section{INTRODUCTION - HEMOSTATIC PERTURBATIONS IN CANCER}

Persistent activation of the coagulation system is amongst the most consistent correlates of advanced malignancy, and its thrombotic consequences remain the second leading cause of cancer related deaths (recently reviewed in ${ }^{1-4}$ ). In spite of the fact that these changes have long been recognized clinically, and studied experimentally, their nature is still poorly understood and rather complex ${ }^{1 ; 3}$, hence the descriptive term of cancer coagulopathy is frequently used to describe them collectively ${ }^{1 ; 3}$. In memory of Armand Trousseau who firmly introduced the notion of cancer-related thrombosis to the literature ${ }^{5}$ (although preceding reports do exist ${ }^{1}$ ), this condition is also sometimes referred to as Trousseau (Trousseau's) syndrome, a term which has historically been reserved to a rather specific set of circumstances, where unexplained thrombotic events preceded the diagnosis of previously unrecognized malignancy ${ }^{6}$. It is argued that the term Trousseau syndrome perhaps should continue to be defined in these strict clinical terms, namely as a cluster of abnormalities that usually include: migratory thrombophlebitis, chronic disseminated intravascular coagulopathy, verrucous endocarditis, microangiopathic anaemia and arterial microemboli, all emerging on the background of occult visceral tumour ${ }^{6}$. At the same time it is recognized that the traditional definition of this important syndrome is essentially retrospective in nature, and thereby of uncertain practical (diagnostic) utility, and also that it may divide what is ultimately a continuum of biological changes (however diverse) ${ }^{6}$.

Indeed, not entirely dissimilar procoagulant events may occur both before and after cancer diagnosis, and cancer patients often develop venous thromboembolism (VTE), including deep vein thrombosis (DVT), pulmonary embolism $(\mathrm{PE})^{7}$, or syndromes that resemble low grade disseminated intravascular coagulation (DIC) ${ }^{27,28}$, or else asymptomatic alterations in laboratory 
tests indicative of the activated coagulation ${ }^{1 ; 2 ; 4}$. Notably, up to $90 \%$ of patients with metastatic cancer are affected by some form of coagulopathy, which is also a cause of considerable morbidity and mortality ${ }^{3 ; 8 ; 9}$.

It is noteworthy that owing to the progress in imaging technology, screening programs and medical education of the public cancer diagnosis is made in many instances at much earlier stage of the disease than would have been the case even a decade ago. Therefore, the contribution of various factors that are thought to be responsible for cancer coagulopathy may undergo some rearrangement. These factors include external influences such as immobility and iatrogenic effects of surgery, central lines or anticancer medication, including novel targeted agents, but is perhaps most strongly defined by the continuous and progressive nature of the disease itself, in its many local, regional and systemic manifestations ${ }^{10}$. While we are awaiting a consensus as to maintaining or broadening the usage of different terms to describe cancer coagulopathy, its nature remains amongst the most fascinating and daunting medical challenges. This article will touch on but one aspect of this rapidly evolving field.

\section{IS CANCER COAGULOPATHY CANCER-SPECIFIC?}

A sound argument could be made that coagulation perturbations and thrombosis in cancer patients could be induced by factors similar to those operative during tissue injury, vascular damage, inflammation, infection, intake of certain types of medication and immobility imposed for various reasons (all present in cancer patients), i.e. cancer coagulopathy could be cancerunspecific in nature. In the other words, the release of procoagulant tissue material into the circulation (e.g. mucins), abnormal vascular barrier, stasis, hypoxia and production of cytokines 
could occur in conjunction of cancer-unrelated injury, surgery, inflammatory bowel disease, still causing an increased risk of thrombosis ${ }^{6}$.

While the contribution of these 'unspecific' triggers to the cancer-related coagulopathy is undeniable, there are several reasons to think that the malignant process adds to these changes another novel, quantitative and qualitative dimension. First, the risk of thrombosis is generally 67 fold greater in cancer patients than in patients with a similar configuration of other risk factors 11. Second, this risk differs in different types of malignancies, even with seemingly similar constellations of 'unspecific' characteristics. For instance, several studies ${ }^{11-13}$ show that the risk of thrombosis is markedly greater in ovarian, pancreatic or brain tumours (glioblastoma) than in head and neck cancer (as reviewed extensively ${ }^{1 ; 2 ; 4}$ ). Also normal haemostasis has recently been shown to be regulated in an organ-specific manner, notably as a result of differences in involvement of tissue factor (TF) ${ }^{14}$. Therefore, the site-specific differences cancer-related risks of thrombosis are inconsistent with the idea of some generic, or external, 'unspecific' mechanism being involved in their causation. Third, as mentioned earlier, the risk of coagulation perturbations increases with cancer progression ${ }^{1 ; 15}$, often without a particular, discrete change in the configuration of 'unspecific' factors. Fourth, these perturbations are often exacerbated ${ }^{1 ; 16}$, or else sometimes alleviated by cancer-specific medication, e.g. by chemotherapy in breast cancer ${ }^{17}$, or in multiple myeloma (MM), especially in conjunction with thalidomide ${ }^{1}$, or by all-trans retinoic acid (ATRA) therapy in acute promyelocytic leukemia (APL), respectively. Fifth, certain relevant elements of cancer pathogenesis have no parallel in other chronic conditions that might be associated with thrombosis, especially as it relates to processes of metastasis, tumour angiogenesis and the underlying mutational changes at the cellular level. These factors are 
especially worthy of closer analysis, as they may illustrate the various levels at which cancer progression affects the cogulation system ${ }^{10}$.

\section{WHAT ARE THE CANCER-SPECIFIC TRIGGERS OF HYPERCOAGULABILITY?}

Malignancies are associated with a host of complex and heterogeneous, localized and systemic changes. These processes are thought to involve a succession of premalignant alterations, followed by cellular diversification and emergence of cancer stem cells (CSCs), also known as tumour initiating cells (TICs) ${ }^{18}$. It is thought that in a conducive tissue context, known as cancer stem cell niche, dormant CSCs cells can be triggered to multiply and produce their mitogenically active cancer cell progeny, the main constituent of the tumour mass ${ }^{18}$. Further tumour growth also depends on generation of the vascular stroma, influx of inflammatory cells, macrophages and well as endothelial and hematopoietic progenitors ${ }^{19 ; 20}$. These local changes in the tissue composition and architecture are associated with a multitude of systemic effects, including activation of bone marrow and formation of premetastatic niches in distant organ sites, eventually followed by overt tumour dissemination ${ }^{21}$. Arguably, at the heart of all these complex changes are the abnormal regulatory networks triggered within cancer cells by mutational (or epigenetic) events that ultimately underlie the activation of oncogenes and inactivation of tumour (and metastasis) suppressors ${ }^{22 ; 23}$.

It is now well established that oncogenic alterations in cancer cells impact various facets of the vascular system. For instance, oncogenic transformation triggers expression of vascular

endothelial growth factor (VEGF) and several other cytokines and chemokines ${ }^{24 ; 25}$, whereby cancer cells become capable of attracting blood vessels and recruitment of inflammatory and 
bone marrow-derived cell of endothelial and hematopoietic origin ${ }^{26}$. These various cells are known to participate in formation of the 'private' tumour microcirculation, namely through processes of tumour angiogenesis, vasculogenesis, blood vessel invasion, vessel cooption and vasculogenic mimicry ${ }^{10 ; 26 ; 27}$.

However, the resulting vascular structures are vastly different from those that emerge during normal development or wound healing, including their architectural ${ }^{28}$, cellular ${ }^{29}$ and molecular ${ }^{30}$ properties. Notably, tumour blood vessels are heterogeneously hyperpermeable, and leaky to plasma-derived macromolecules, including coagulation factors, which thereby come into direct contact with the procoagulant extravascular microenvironment of cancer cells and tumour stroma 4;10. In addition, the actions of VEGF ${ }^{25 ; 31}$, inflammatory cytokines (e.g. tumour necrosis factor alpha) and other stimuli ${ }^{32}$ may turn on the expression of tissue factor (TF) in normally anticoagulant endothelial cells, thereby further compromising their barrier function ${ }^{33 ; 34}$.

Procoagulant tumour cells not only interact with extravascular clotting factors, but also physically enter the vascular compartment through processes of blood vessel invasion, microscpoic intravasation, or as circulating metastatic deposits ${ }^{35}$. In addition tumor-related proteins, including TF, may enter the blood stream as cargo of procoagulant microvesicles/microparticles ${ }^{7 ; 36 ; 37}$. The sum of these emerging new points of abnormal contact between the tumour mass and the vascular system (tumour-vascular interface), is likely to strongly influence cancer coagulopathy, their nature is, for the most part, unique to cancer ${ }^{38}$ and, we postulate that their causative stimulus lies to a large extent with cancer causing oncogenic mutations ${ }^{10}$. 


\section{ONCOGENE-DEPENDENT ALTERATIONS AFFECTING THE COAGULATION SYSTEM}

The impact of the oncogenic pathways on procoagulant events in cancer has only recently been recognized ${ }^{39}$, and can be viewed as either indirect or direct in nature. In the first instance, it is reasoned that the wide spread changes in gene expression profiles induced by the malignant transformation also include the various modifiers of the tumor-vascular interface, resulting in changes impacting the haemostatic system. Paradigmatic in this regard is the influence exerted by the loss of the p53 tumor suppressor gene. Seminal studies of Bouck and collaborators established for the first time that intrinsic changes in cancer cells, and not necessarily the microenvironment, are primary inducers of the angiogenic phenotype, here epitomized by deregulation of the antiangiogenic protein thrombospondin 1 (TSP-1) ${ }^{40-42}$. Subsequent studies revealed the key role of ras oncogene in regulation of both VEGF, the central inducer of angiogenesis and vasculogenesis, and TSP-1 its antithetical angiogenesis inhibitor ${ }^{24 ; 25 ; 43}$. Collectively, these and numerous follow up studies involving over 20 different oncogenic lesions and several of their downstream pro- and anti-angiogenic growth factors, cytokines and polypeptides (cancer cell angiome) provided ample demonstration that the consequences of cancer-causing genetic events transcend cellular boundaries, and through paracrine influences lead to formation of abnormal, static, leaky, TF expressing and sometimes occlusive intratumoral blood vessels. This, in turn, may be one of the oncogene-dependent sources of pro-coagulant events associated with cancer ${ }^{10}$.

There is also mounting evidence that intracellular signalling cascades triggered downstream of mutant oncogenes and tumor suppressors directly control the ability of cancer cells to express (sometimes ectopically) several genes related to the coagulation or fibrinolytic systems, i.e. the 
cancer cell coagulome ${ }^{10}$. What are the most important activities in this regard remains to be established, but Table 1 summarizes the presently available, albeit still limited, literature. Thus, evidence exists that oncogenic lesions impact the expression of professional elements of the coagulation (e.g. TF) and fibrinolytic pathways (urokinmase/uPA), which are otherwise normally expressed in various tissues. However, cancer cells also acquire the ability to express coagulation factors ectopically. For instance, factor VII was recently found to be expressed by several different liver-unrelated tumour cell lines ${ }^{44}$. This is interesting as activation of this factor and its binding to TF on the same cells could potentiate their procoagulant properties and, at the same time contribute to the autocrine (e.g. PAR-2-mediated) TF signalling ${ }^{44}$. Similarly, thrombin-like protein was found to be produced by a human breast cancer cell line ${ }^{45}$. If confirmed, this finding could suggest the existence of TF-unrelated mechanisms of procoagulant conversion of these cancer cells, and potentially, once again, their autocrine stimulation via PAR-1 ${ }^{44}$. In both of these cases the ectopic production of coagulation factors appears to be transformation-specific, as such production is largely restricted to cancer cells. If so, this would implicitly suggest an involvement of some, presently unknown, oncogenic events. The third category of cancer- and oncogene-dependent procoagulant factors are ones in which this putative activity has no known role in normal haemostasis. The case in point are cancer-related mucins, some which are targets of oncogenes and have been previously implicated in the activation of the coagulation system 6;46. Fourth, class of factors is composed of the protease known as cancer procoagulant (CP). There is presently no data as to the regulation of CP by oncogenic events, and the discussion of the mechanisms leading to the release of this interesting factor would be more informative once its origin and identity are understood in more detail. Fifth category of procoagulant activities released by cancer cells under the influence of oncogenic events are TF-containing membrane- 
related tumour microvesicles (Table 1). Recent studies revealed that oncogenic events, such as mutations of p53, or activation of epidermal growth factor receptor (EGFR) and other changes may drive the release of microvesicular TF into the circulation ${ }^{37}$, a process that involves both stimulation of the cellular vesiculation process ${ }^{47}$ and well as oncogene-driven overexprssion of TF itself ${ }^{37 ; 48}$. The latter process is worth considering in more detail as TF represents an interesting paradigm for the control of cancer coagulopathy, due to its pivotal role in the coagulation cascade, cellular association and well-recognized biological and signalling activity 44 .

\section{REGULATION OF TISSUE FACTOR BY ONCOGENIC PATHWAYS}

Tissue factor (TF) is a $47 \mathrm{kDa}$ transmembrane cellular receptor for the blood borne coagulation protease, factor VIIa (FVIIa) ${ }^{49 ; 50}$. As TF is normally absent in the vascular lumen this interaction can only occur upon vascular injury, abnormal TF expression on endothelial cells (e.g during angiogenesis), or after entry into the blood stream of a large number of TF expressing material, such as TF expressing cells and microvesicles ${ }^{50-53}$. Formation of the TF/VIIa complex $^{50 ; 52}$ triggers proteolytic conversion of circulating factor X (FX) to an active form (FXa) (along with activation of FIX). FXa activates small amounts of prothrombin (FII) to thrombin (FIIa $)^{54}$. A subsequent burst of thrombin activity is facilitated by platelets, and factors Va, VIIIa and IXa leading to conversion of soluble fibrinogen into insoluble fibrin ${ }^{54}$, activation of protease-activated (G protein-coupled) receptors (PARs), followed by further recruitment of platelets and rapid clot formation ${ }^{55}$. These processes are kept in check by several opposing influences ${ }^{52 ; 54}$, including: tissue factor pathway inhibitor (TFPI), protein C, antithrombin ${ }^{52}$ and the fibrinolytic system ${ }^{54 ; 56}$. 
TF expression is not restricted to cancer and can be detected on extravascular smooth muscle and connective tissue cells surrounding blood vessels (hemostatic envelope), and in association with inflammatory cells, especially upon activation ${ }^{32}$. However, it is also true that TF activity on the surface of cancer cells can be up to 1000 fold greater than that associated with their normal counterparts ${ }^{34: 59}$. Indeed, $\mathrm{TF}$ is overexpressed in many cancers, especially at their late stages of progression ${ }^{34 ; 60-64}$, where the degree of TF-positivity often correlates with poor prognosis ${ }^{65}$, metastasis ${ }^{66}$, high microvascular density (MVD), and expression of VEGF ${ }^{67}$.

While it has been postulated that TF may be expressed as a result of tumour hypoxia or stimulation with inflammatory cytokines ${ }^{4 ; 68}$, may types of cancer cells express this receptor constitutively, including in cell culture, i.e. in the absence of hypoxia or inflammation, and often as a function of their malignant transformation ${ }^{10 ; 37}$. This led to the suggestion that oncogenic lesions in the cancer cell genome may contribute to their TF overexpression and procoagulant conversion, in very much the same way as these lesions control the tumor-related angiogenic phenotype and neovascularization ${ }^{39}$. Indeed, studies involving human colorectal cancer cells (CRC) first revealed that the succession of oncogenic mutations affecting K-ras proto-oncogene and p53 tumor suppressor (two pivotal events during CRC progression) trigger the corresponding, stepwise increases in TF gene expression, protein production, procoagulant activity and shedding of TF-containing tumour-cell derived microvesicles ${ }^{37}$. Interestingly, when two isogenic and tumourigenic CRC cell lines with different p53 status were compared in an in vivo xenograft assay, it was found at the same tumour size that the cells that have lost p53 expression were more proficient in shedding microvesicular TF into the circulation of the tumour 
bearing mice than their $p 53$ proficient counterparts ${ }^{37}$. As K-ras mutations were present in both tumour types, it is unclear whether this effect of p53 is independent, or requires the concomitant activation of the Ras pathway.

In the absence of ras gene mutations Ras pathway may become activated via upstream stimulation of protooncogenic receptor tyrosine kinases (RTKs), such as members of the ErbB family, including EGFR and or ErbB2/HER-2. These RTKs are frequently involved (activated) in epidermal, epithelial, brain and other human malignancies ${ }^{69}$ and, as recently demonstrated, their activation robustly triggers overexpression of $\mathrm{TF}{ }^{48 ; 70 ; 71}$. For instance, copious amounts of TF are produced by the human, epithelial, squamous cell carcinoma cell line, A431, which also contains an amplified wild type EGFR gene and overexpress the oncogenic EGFR protein. Moreover, treatment of these cells with EGFR agonists, such as transforming growth factor alpha (TGF $\alpha$ ), leads to further dramatic increases in TF gene expression, protein production and procoagulant activity, while several different pharmacological inhibitors of EGFR (C225, AG1478, CI-1033) induce the opposite effect $\left({ }^{48}\right.$ and Milsom \& Rak - unpublished data).

Oncogenic activity of EGFR in A431 cells not only drives the cell-associated ovrerexpression of $\mathrm{TF}$, but also the release of this receptor into the cellular micromilieu, as membrane microvesicles 72. The significance of TF shedding is in its independent procoagulant actions ${ }^{53}$ but also in the uptake of the TF containing microvesicles by other cells and platelets ${ }^{7 ; 73}$. In cancer, such mechanism could lead to propagation of the procoagulant potential, both within the tumour and systemically. Moreover, we postulated earlier that the intercellular transfer of TF as microvesicle cargo may represent an interesting paradigm for 'sharing' this and other cellular receptors, 
between the cells, a process that could include also the oncogenic RTKs (Yu and Rak unpublished). Indeed, when microvesicles derived from A431 cells were incubated with TFnegative mouse endothelial cells this led to a transfer of both fluorescently labelled tumour cell membrane material and the associated human TF activity (Yu, Milsom \& Rak unpublished). Interestingly, our subsequent studies based on this paradigm revealed that indeed, other receptors could be transferred between the cells in a similar manner. For instance, oncogenic EGFR was found to be incorporated into the cargo of tumour related exosomes ${ }^{74}$ and microvesicles, and in that form could traffic between the adjacent cells ${ }^{47}$. The consequences of this latter process for cancer related coagulopathy remain presently unclear. However, blood borne TF-containing microvesicles are increasingly viewed as a possible source of prognostic information regarding the risk of thrombosis in cancer patients. This notion is consistent with the suggestion that cancer progression and the related oncogenic events influence the risk of thrombosis by impacting TF expression ${ }^{37}$, cellular vesiculation ${ }^{37}$ and possibly the intercellular microvesicle transfer ${ }^{47}$.

$\mathrm{TF}^{75}$ and EGFR ${ }^{76}$ are highly expressed in human glioblastoma multiforme (GBM), and are both of potential prognostic significance. In particular, the presence of the ligand-independent EGFR mutant (EGFRvIII) signifies the transition from lower grade disease to a high-grade aggressive $\mathrm{GBM}^{76}$, of which vascular proliferation, necrosis and thrombosis are important hallmarks ${ }^{77}$. To explore the possible linkage between EGFRvIII and the prothromotic characteristics of GBM cells we employed an indolent glioma cell line (U373), which expresses low levels of TF. When these cells were transfected with EGFRvIII cDNA we observed a dramatic increase in TF expression and procoagulant activity, properties that were readily reversible upon exposure to the several EGFR inhibitors (Milsom, Yu, Magnus \& Rak unpublished). 
Although EGFR may play a significant role in TF expression in primary GBM, other genetic events are clearly operative in this disease, and could contribute to its hypercoagulable nature ${ }^{77}$. Pioneering work in this regard was recently published by Brat, Rong and colleagues who documented the impact associated with the loss of the PTEN tumor suppressor on hypoxiaregulated levels of TF in astrocytic and GBM cells ${ }^{78}$. PTEN is a lipid phosphatise and tensin homologue localized on chromosome ten, which is mutated, lost or silenced in up to $70 \%$ of all GBM. PTEN plays a crucial role in down modulating the excessive activity of the PI3K/Akt cascade, downstream of several growth and survival regulating receptors, including in cells harbouring EGFR and EGFRvIII oncogenes ${ }^{69 ; 76 ; 79}$. In their study Rong et al demonstrated that loss of PTEN and hypoxia cooperate in upregulation of TF in astrocytic cells, likely in a manner that involves Akt and hypoxia responsive transcription factor Egr-1 ${ }^{78}$. As loss of PTEN often overlaps in a prognostically significant manner with the activation of the EGFR/EGFRvIII pathway ${ }^{80}$, it is of interest whether both of these lesions also interact in regulating TF expression and coagulopathy of GBM cells and are linked to thrombotic events in the respective GBM patients. It is also of great interest whether $\mathrm{TF}$ regulation by these oncogenic pathways influences in a more direct manner the biology of the disease.

\section{COMPLEXITY OF PROCOAGULANT CHANGES REGULATED BY ONCOGENES}

While TF serves as an instructive paradigm to consider the role of oncogenic pathways in the regulation of the cancer coagulome, the scope of these latter changes is likely much wider. For instance, while mutant ras upregulates TF in various settings, it also regulates the expression of fibrinolytic activities (UPA), a property that may explain why massive vascular occlusion and 
thrombosis is relatively infrequent, even in highly TF-positive tumors ${ }^{10}$. However, there are instances, at least in experimental settings, where a single oncogenic lesion may provoke an overt and extremely severe thrombohaemorrhagic syndrome. The case in point is the recent elegant study by Boccaccio et al, in which c-MET oncogene was introduced into the mouse liver by a lentiviral vector, and the resulting neoplastic growth was found to precipitate a life threatening thrombosis, ostensibly due to upregulation of PAI-1 and COX-2 ${ }^{81}$. While this may represent an extreme case, with few direct parallels in the clinical context, somewhat milder thrombotic complications do emerge as a result of oncogenic activity in patients with certain types of malignant diseases. For instance, in acute promyelocytic leukemia (APL), the $P M L$ -

$R A R a$ oncogene plays a pivotal transforming role ${ }^{82 ; 83}$, which can be partially blocked by treatment with all-trans retinoid acid (ATRA) ${ }^{82}$. Interestingly, this treatment also leads to the resolution of the APL-associated coagulopathy, possibly due to downregulation of TF on leukemic cells, along with other changes ${ }^{82}$. These examples merely scratch the surface of what is likely to be a much larger network of molecular interactions that influence haemostatic parameters in cancer patients. Until more data is available, in can only be speculated that in addition to TF, also other professional (ectopic FVII) and opportunistic (mucins, adhesion molecules) procoagulant molecules could be regulated by the oncogenic transformation and contribute to hypercoagulability.

\section{CONCLUSIONS AND IMPLICATIONS}

The 'oncogene hypothesis' provides a workable platform to understand the cancer-specific alterations in the haemostatic system, however it is hardly the ultimate answer to the puzzle of cancer coagulopathy. As in the case of other cancer related processes, oncogenic pathways that 
control expression of TF and other coagulation-related effectors intersect at many levels with pathways of stress response, hypoxia ${ }^{68}$ and cellular differentiation ${ }^{84}$. The latter regulation is of particular interest as it controls how oncogene-harbouring cells acquire properties of cancer stem cells (CSCs/TICs) or become their limited proegeny ${ }^{18}$. In this regard it was recently postulated that the procoagulant microenvironment may serve as a provisional CSC niche and thereby promote disease progression ${ }^{84}$.

Thus, it is increasingly appreciated that cancer coagulopathy may contribute not only to thrombotic side effects but also to disease progression and aggressiveness as such ${ }^{8-10 ; 85 ; 86}$. This is highlighted by improved survival of subsets of patients included in several recent clinical trials involving administration of low molecular weight heparin ${ }^{1 ; 87-89}$. While this is encouraging, it is also possible that the pathogenesis of cancer-related coagulopathy is sufficiently dissimilar from conditions found in cardiovascular, orthopaedic and other contexts, that it may benefit from including additional cancer-specific measures, e.g. targeted agents to obliterate oncogene-driven expression of TF, and/or TF antagonists ${ }^{90}$. It is likely that a better understanding of cancer coagulopathy may provide additional insights into the pathogenesis of cancer ${ }^{10}$.

\section{ACKNOWLEDGEMENTS}

This work was supported by grants to J. R. from the National Cancer Institute of Canada (NCIC), Canadian Cancer Society and the Terry Fox Foundation. J. R. is the recipient of the Jack Cole Chair in Pediatric Oncology at McGill University. The infrastructure of the MCHRI has been supported 
through funds from FRSQ. We are indebted to our collaborators, Drs Nigel Mackman, Abhijit Guha, Jeffrey Weitz and Petr Klement, and above all to our families for their continuous support and understanding. JR owes special thanks to Danuta and Anna Rak. 
Table 2: Linkage between oncogenic events and procoagulant phenotype of cancer cells

\begin{tabular}{|c|c|c|c|}
\hline \multicolumn{2}{|c|}{ Genetic Influence } & Consequence of Deregulation & References \\
\hline \multirow{15}{*}{ Oncogenes } & K-ras & Upregulation of TF in human CRC cells & \\
\hline & H-ras & Downregulation of TFPI 2 & \\
\hline & H-ras & Upregulation of uPA & $92 ; 93$ \\
\hline & H-ras & Downregulation of uPA in invasive cells & 94 \\
\hline & H-ras & Upregulation of mucins & 95 \\
\hline & src & Upregulation of $\mathrm{TF}$ & 96 \\
\hline & EGFR & Upregulation of TF & 48 \\
\hline & EGFRvIII & Upregulation of TF & $\begin{array}{l}\text { Milsom, Yu, Magnus \& } \\
\text { Rak unpublished }\end{array}$ \\
\hline & RGFRvIII & $\begin{array}{l}\text { Increase in vesiculation (may contribute to } \\
\text { release of procoagulant activity) }\end{array}$ & 47 \\
\hline & HER-2 & Increase in TF expression & (Yu \& Rak unpublished) \\
\hline & HER-2 & Upregulation of mucins & 95 \\
\hline & Unknown & Ectopic expression of in cancer FVII & 97 \\
\hline & Unknown & Ectopic expression of thrombin-like protein & 45 \\
\hline & PML-RARa & TF-dependent coagulopathy & 82 \\
\hline & c-MET & Deregulation of PAI-1 and COX-2 & 81 \\
\hline \multirow{3}{*}{$\begin{array}{l}\text { Tumour } \\
\text { Suppressors }\end{array}$} & P53 & Upregulation of TF in human CRC cells & 37 \\
\hline & P53 & $\begin{array}{l}\text { Increase in release TF containing } \\
\text { microvesicles into the circulation }\end{array}$ & 37 \\
\hline & PTEN & Upregulation of TF & 78 \\
\hline
\end{tabular}




\section{References}

1. Buller HR, van Doormaal FF, van Sluis GL, Kamphuisen PW. Cancer and thrombosis: from molecular mechanisms to clinical presentations. J.Thromb.Haemost. 2007;5 Suppl 1:246-254.

2. Zwicker JI, Furie BC, Furie B. Cancer-associated thrombosis. Crit Rev.Oncol.Hematol. 2007;62:126-136.

3. Falanga A. Thrombophilia in cancer. Semin.Thromb.Hemost. 2005;31:104-110.

4. Rickles FR. Mechanisms of cancer-induced thrombosis in cancer.

Pathophysiol.Haemost.Thromb. 2006;35:103-110.

5. Trousseau, A. Phlegmasia alba dolens. Clinique Medicale de l'Hotel -Dieu de Paris. The Sydenham Society 2nd, 654-712. 1865. Paris, France.

Ref Type: Serial (Book,Monograph)

6. Varki A. Trousseau's syndrome: multiple definitions and multiple mechanisms. Blood 2007;110:1723-1729.

7. Tesselaar ME, Romijn FP, van dL, I et al. Microparticle-associated tissue factor activity: a link between cancer and thrombosis? J.Thromb.Haemost. 2007;5:520-527.

8. Rickles FR, Patierno S, Fernandez PM. Tissue factor, thrombin, and cancer. Chest 2003;124:58S-68S.

9. Petralia GA, Lemoine NR, Kakkar AK. Mechanisms of disease: the impact of antithrombotic therapy in cancer patients. Nat.Clin.Pract.Oncol. 2005;2:356-363. 
10. Rak J, Yu JL, Luyendyk J, Mackman N. Oncogenes, trousseau syndrome, and cancerrelated changes in the coagulome of mice and humans. Cancer Res. 2006;66:1064310646.

11. Blom JW, Doggen CJ, Osanto S, Rosendaal FR. Malignancies, prothrombotic mutations, and the risk of venous thrombosis. JAMA 2005;293:715-722.

12. Svendsen E, Karwinski B. Prevalence of pulmonary embolism at necropsy in patients with cancer. J.Clin.Pathol. 1989;42:805-809.

13. Levitan N, Dowlati A, Remick SC et al. Rates of initial and recurrent thromboembolic disease among patients with malignancy versus those without malignancy. Risk analysis using Medicare claims data. Medicine (Baltimore) 1999;78:285-291.

14. Mackman N. Tissue-specific hemostasis in mice. Arterioscler.Thromb.Vasc.Biol. 2005;25:2273-2281.

15. Iversen LH, Thorlacius-Ussing O. Systemic coagulation reactivation in recurrence of colorectal cancer. Thromb.Haemost. 2003;89:726-734.

16. Kuenen BC, Rosen L, Smit EF et al. Dose-Finding and Pharmacokinetic Study of Cisplatin, Gemcitabine, and SU5416 in Patients With Solid Tumors. J Clin.Oncol. 2002;20:1657-1667.

17. Rickles FR, Levine MN. Venous thromboembolism in malignancy and malignancy in venous thromboembolism. Haemostasis 1998;28 Suppl 3:43-9:43-49. 
18. Reya T, Morrison SJ, Clarke MF, Weissman IL. Stem cells, cancer, and cancer stem cells. Nature 2001;414:105-111.

19. Folkman J, Kalluri R. Tumor Angiogenesis. In: Kufe DW, Pollock RE, Weichselbaum RR et al., eds. Cancer Medicine. Hamilton, London: BC Decker Inc.; 2003:161-194.

20. Brown LF, Guidi AJ, Schnitt SJ et al. Vascular stroma formation in carcinoma in situ, invasive carcinoma, and metastatic carcinoma of the breast. Clin.Cancer Res. 1999;5:1041-1056.

21. Kaplan RN, Riba RD, Zacharoulis S et al. VEGFR1-positive haematopoietic bone marrow progenitors initiate the pre-metastatic niche. Nature. 2005;438:820-827.

22. Hanahan D, Weinberg RA. The hallmarks of cancer. Cell 2000;100:57-70.

23. Bishop JM. Cancer: the rise of the genetic paradigm. Genes Dev. 1995;9:1309-1315.

24. Rak J, Yu JL, Klement G, Kerbel RS. Oncogenes and angiogenesis: signaling threedimensional tumor growth. J.Investig.Dermatol.Symp.Proc. 2000;5:24-33.

25. Rak J, Mitsuhashi Y, Bayko L et al. Mutant ras oncogenes upregulate VEGF/VPF expression: implications for induction and inhibition of tumor angiogenesis. Cancer Res. 1995;55:4575-4580.

26. Kerbel RS. Tumor angiogenesis. N.Engl.J.Med. 2008;358:2039-2049.

27. Carmeliet P. Angiogenesis in life, disease and medicine. Nature. 2005;438:932-936. 
28. Jain RK, di TE, Duda DG et al. Angiogenesis in brain tumours. Nat.Rev.Neurosci. 2007;8:610-622.

29. Ocak I, Baluk P, Barrett T, McDonald DM, Choyke P. The biologic basis of in vivo angiogenesis imaging. Front Biosci. 2007;12:3601-3616.

30. Seaman S, Stevens J, Yang MY et al. Genes that distinguish physiological and pathological angiogenesis. Cancer Cell 2007;11:539-554.

31. Dvorak HF. Vascular permeability factor/vascular endothelial growth factor: a critical cytokine in tumor angiogenesis and a potential target for diagnosis and therapy. $\mathrm{J}$ Clin.Oncol. 2002;20:4368-4380.

32. Mackman N. Role of tissue factor in hemostasis, thrombosis, and vascular development. Arterioscler.Thromb.Vasc.Biol. 2004;24:1015-1022.

33. Mechtcheriakova D, Schabbauer G, Lucerna M et al. Specificity, diversity, and convergence in VEGF and TNF-\{alpha\} signaling events leading to tissue factor upregulation via EGR-1 in endothelial cells. FASEB J. 2001;15:230-242.

34. Contrino J, Hair G, Kreutzer DL, Rickles FR. In situ detection of tissue factor in vascular endothelial cells: correlation with the malignant phenotype of human breast disease. Nat.Med. 1996;2:209-215.

35. Fidler IJ. The pathogenesis of cancer metastasis: the 'seed and soil' hypothesis revisited. Nat.Rev.Cancer 2003;3:453-458. 
36. Dvorak HF, Quay SC, Orenstein NS et al. Tumor shedding and coagulation. Science $1981 ; 212: 923-924$.

37. Yu JL, May L, Lhotak V et al. Oncogenic events regulate tissue factor expression in colorectal cancer cells: implications for tumor progression and angiogenesis. Blood 2005;105:1734-1741.

38. Rak J, Milsom C, Yu J. Tissue factor in cancer. Curr.Opin.Hematol. 2008;in press:

39. Rak J, Klement G. Impact of oncogenes and tumor suppressor genes on deregulation of hemostasis and angiogenesis in cancer. Cancer Metastasis Rev. 2000;19:93-96.

40. Rastinejad F, Polverini PJ, Bouck N. Regulation of the activity of a new inhibitor by angiogenesis by a cancer suppressor gene. Cell 1989;56:345-355.

41. Dameron KM, Volpert OV, Tainsky MA, Bouck N. The p53 tumor suppressor gene inhibits angiogenesis by stimulating the production of thrombospondin. Cold Spring Harb.Symp.Quant.Biol. 1994;59:483-9:483-489.

42. Bouck N, Stellmach V, Hsu SC. How tumors become angiogenic. Adv.Cancer Res. 1996;69:135-174.

43. Grugel S, Finkenzeller G, Weindel K, Barleon B, Marme D. Both v-Ha-ras and v-raf stimulate expression of the vascular endothelial growth factor in NIH 3T3 cells. J.Biol.Chem. 1995;270:25915-25919.

44. Ruf W. Redundant signaling of tissue factor and thrombin in cancer progression? J.Thromb.Haemost. 2007;5:1584-1587. 
45. Schulze EB, Hedley BD, Goodale D et al. The thrombin inhibitor Argatroban reduces breast cancer malignancy and metastasis via osteopontin-dependent and osteopontinindependent mechanisms. Breast Cancer Res.Treat. 2007

46. Pineo GF, Brain MC, Gallus AS et al. Tumors, mucus production, and hypercoagulability. Ann.N.Y.Acad.Sci. 1974;230:262-270.

47. Al-Nedawi K, Meehan B, Micallef J et al. Intercellular transfer of the oncogenic receptor EGFRvIII by microvesicles derived from tumour cells. Nat.Cell Biol. 2008;10:619-624.

48. Yu JL, May L, Klement P, Weitz JI, Rak J. Oncogenes as regulators of tissue factor expression in cancer: implications for tumor angiogenesis and anti-cancer therapy. Semin.Thromb.Hemost. 2004;30:21-30.

49. Mackman N, Morrissey JH, Fowler B, Edgington TS. Complete sequence of the human tissue factor gene, a highly regulated cellular receptor that initiates the coagulation protease cascade. Biochemistry 1989;28:1755-1762.

50. Chen J, Bierhaus A, Schiekofer S et al. Tissue factor--a receptor involved in the control of cellular properties, including angiogenesis. Thromb.Haemost. 2001;86:334-345.

51. Fernandez PM, Rickles FR. Tissue factor and angiogenesis in cancer. Curr.Opin.Hematol. 2002;9:401-406.

52. Morrissey JH. Tissue factor: an enzyme cofactor and a true receptor. Thromb.Haemost. 2001;86:66-74. 
53. Giesen PL, Rauch U, Bohrmann B et al. Blood-borne tissue factor: another view of thrombosis. Proc.Natl.Acad.Sci.U.S.A 1999;96:2311-2315.

54. Colman RW, Marder VJ, Salzman EW, Hirsh J. Overview of Hemostasis. In: Coleman RB, Hirsh J, Marder VJ, Salzman JB, eds. Hemostasis and Thrombosis: Basic Principles and Clinical Practice. Philadelphia: Lippincott Company; 1994:3-18.

55. Coughlin SR. Protease-activated receptors in vascular biology. Thromb.Haemost. 2001;86:298-307.

56. Degen JL. Genetic interactions between the coagulation and fibrinolytic systems. Thromb.Haemost. 2001;86:130-137.

57. Lijnen HR. Plasmin and matrix metalloproteinases in vascular remodeling. Thromb.Haemost. 2001;86:324-333.

58. Al-Nedawi KN, Czyz M, Bednarek R et al. Thymosin beta 4 induces the synthesis of plasminogen activator inhibitor 1 in cultured endothelial cells and increases its extracellular expression. Blood. 2004;103:1319-1324.

59. Shoji M, Abe K, Nawroth PP, Rickles FR. Molecular mechanisms linking thrombosis and angiogenesis in cancer. Trends in Cardiovascular Medicine 199752-59.

60. Wojtukiewicz MZ, Sierko E, Klement P, Rak J. The hemostatic system and angiogenesis in malignancy. Neoplasia. 2001;3:371-384. 
61. Ueno T, Toi M, Koike M, Nakamura S, Tominaga T. Tissue factor expression in breast cancer tissues: its correlation with prognosis and plasma concentration. Br.J.Cancer 2000;83:164-170.

62. Sawada M, Miyake S, Ohdama S et al. Expression of tissue factor in non-small-cell lung cancers and its relationship to metastasis. Br.J.Cancer 1999;79:472-477.

63. Kakkar AK, Lemoine NR, Scully MF, Tebbutt S, Williamson RC. Tissue factor expression correlates with histological grade in human pancreatic cancer. Br.J.Surg. 1995;82:1101-1104.

64. Koomagi R, Volm M. Tissue-factor expression in human non-small-cell lung carcinoma measured by immunohistochemistry: correlation between tissue factor and angiogenesis. Int.J.Cancer 1998;79:19-22.

65. Seto S, Onodera $\mathrm{H}$, Kaido $\mathrm{T}$ et al. Tissue factor expression in human colorectal carcinoma: correlation with hepatic metastasis and impact on prognosis. Cancer 2000;88:295-301.

66. Shigemori C, Wada H, Matsumoto K et al. Tissue factor expression and metastatic potential of colorectal cancer. Thromb.Haemost. 1998;80:894-898.

67. Nakasaki T, Wada H, Shigemori C et al. Expression of tissue factor and vascular endothelial growth factor is associated with angiogenesis in colorectal cancer. Am.J Hematol. 2002;69:247-254. 
68. Denko NC, Giaccia AJ. Tumor hypoxia, the physiological link between Trousseau's syndrome (carcinoma-induced coagulopathy) and metastasis. Cancer Res. 2001;61:795798.

69. Citri A, Yarden Y. EGF-ERBB signalling: towards the systems level. Nat.Rev.Mol.Cell Biol. 2006;7:505-516.

70. Rak J, Milsom C, May L, Klement P, Yu J. Tissue Factor in Cancer and Angiogenesis: The Molecular Link between Genetic Tumor Progression, Tumor Neovascularization, and Cancer Coagulopathy. Semin.Thromb.Hemost. 2006;32:54-70.

71. Milsom C, Yu J, May L et al. The role of tumor-and host-related tissue factor pools in oncogene-driven tumor progression. Thromb.Res. 2007;120 Suppl 2:S82-S91.

72. Yu JL, Rak JW. Shedding of tissue factor (TF)-containing microparticles rather than alternatively spliced TF is the main source of TF activity released from human cancer cells. J Thromb.Haemost. 2004;2:2065-2067.

73. Del C, I, Shrimpton CN, Thiagarajan P, Lopez JA. Tissue-factor-bearing microvesicles arise from lipid rafts and fuse with activated platelets to initiate coagulation. Blood. 2005;106:1604-1611.

74. Sanderson MP, Keller S, Alonso A et al. Generation of novel, secreted epidermal growth factor receptor (EGFR/ErbB1) isoforms via metalloprotease-dependent ectodomain shedding and exosome secretion. J.Cell Biochem. 2008;103:1783-1797. 
75. Guan M, Jin J, Su B, Liu WW, Lu Y. Tissue factor expression and angiogenesis in human glioma. Clin.Biochem. 2002;35:321-325.

76. Ohgaki H, Kleihues P. Genetic pathways to primary and secondary glioblastoma. Am.J.Pathol. 2007;170:1445-1453.

77. Brat DJ, Van Meir EG. Vaso-occlusive and prothrombotic mechanisms associated with tumor hypoxia, necrosis, and accelerated growth in glioblastoma. Lab Invest 2004;84:397-405.

78. Rong Y, Post DE, Pieper RO et al. PTEN and hypoxia regulate tissue factor expression and plasma coagulation by glioblastoma. Cancer Res. 2005;65:1406-1413.

79. Furnari FB, Fenton T, Bachoo RM et al. Malignant astrocytic glioma: genetics, biology, and paths to treatment. Genes Dev. 2007;21:2683-2710.

80. Mellinghoff IK, Wang MY, Vivanco I et al. Molecular determinants of the response of glioblastomas to EGFR kinase inhibitors. N.Engl.J.Med. 2005;353:2012-2024.

81. Boccaccio C, Sabatino G, Medico E et al. The MET oncogene drives a genetic programme linking cancer to haemostasis. Nature 2005;434:396-400.

82. Tallman MS, Lefebvre P, Baine RM et al. Effects of all-trans retinoic acid or chemotherapy on the molecular regulation of systemic blood coagulation and fibrinolysis in patients with acute promyelocytic leukemia. J Thromb.Haemost. 2004;2:1341-1350.

83. Pandolfi PP. Oncogenes and tumor suppressors in the molecular pathogenesis of acute promyelocytic leukemia. Hum.Mol.Genet. 2001;10:769-775. 
84. Milsom C, Anderson GM, Weitz JI, Rak J. Elevated tissue factor procoagulant activity in CD133-positive cancer cells. J.Thromb.Haemost. 2007;5:2550-2552.

85. Belting M, Ahamed J, Ruf W. Signaling of the tissue factor coagulation pathway in angiogenesis and cancer. Arterioscler.Thromb.Vasc.Biol. 2005;25:1545-1550.

86. Zacharski LR. Malignancy as a solid-phase coagulopathy: implications for the etiology, pathogenesis, and treatment of cancer. Semin.Thromb.Hemost. 2003;29:239-246.

87. Lee AY, Rickles FR, Julian JA et al. Randomized comparison of low molecular weight heparin and coumarin derivatives on the survival of patients with cancer and venous thromboembolism. J Clin.Oncol. 2005;23:2123-2129.

88. Kakkar AK, Levine MN, Kadziola Z et al. Low molecular weight heparin, therapy with dalteparin, and survival in advanced cancer: the fragmin advanced malignancy outcome study (FAMOUS). J Clin.Oncol. 2004;22:1944-1948.

89. Altinbas M, Coskun HS, Er O et al. A randomized clinical trial of combination chemotherapy with and without low-molecular-weight heparin in small cell lung cancer. J.Thromb.Haemost. 2004;2:1266-1271.

90. Versteeg HH, Schaffner F, Kerver $\mathrm{M}$ et al. Inhibition of tissue factor signaling suppresses tumor growth. Blood 2008;111:190-199.

91. Izumi H, Takahashi C, Oh J, Noda M. Tissue factor pathway inhibitor-2 suppresses the production of active matrix metalloproteinase-2 and is down-regulated in cells harboring activated ras oncogenes. FEBS Lett. 2000;481:31-36. 
92. Mazzieri R, Furlan F, D'Alessio S et al. A direct link between expression of urokinase plasminogen activator receptor, growth rate and oncogenic transformation in mouse embryonic fibroblasts. Oncogene 2007;26:725-732.

93. Zhao Y, Xiao A, Dipierro CG et al. H-Ras increases urokinase expression and cell invasion in genetically modified human astrocytes through Ras/Raf/MEK signaling pathway. Glia 2008;56:917-924.

94. Pakneshan P, Szyf M, Rabbani SA. Methylation and inhibition of expression of uPA by the RAS oncogene: divergence of growth control and invasion in breast cancer cells. Carcinogenesis 2005;26:557-564.

95. Scibetta AG, Albanese I, Morris J et al. Regulation of MUC1 expression in human mammary cell lines by the c-ErbB2 and ras signaling pathways. DNA Cell Biol. 2001;20:265-274.

96. Jahner D, Hunter T. The stimulation of quiescent rat fibroblasts by v-src and v-fps oncogenic protein-tyrosine kinases leads to the induction of a subset of immediate early genes. Oncogene 1991;6:1259-1268.

97. Koizume S, Jin MS, Miyagi E et al. Activation of cancer cell migration and invasion by ectopic synthesis of coagulation factor VII. Cancer Res. 2006;66:9453-9460. 


\section{FIGURES}

\section{Figure 1.}

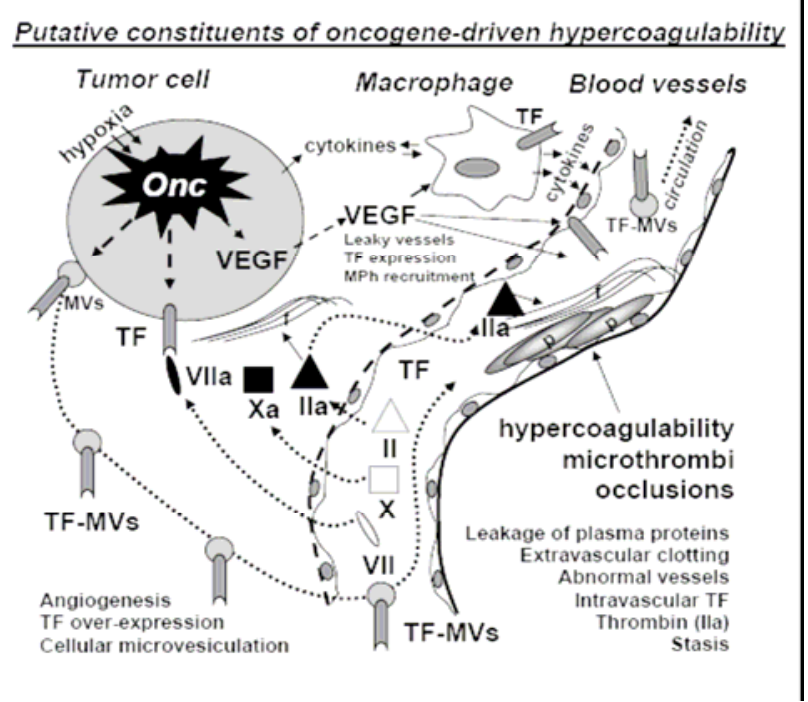

